\title{
Ty1 Sequence with Enhancer and Mating-Type-Dependent Regulatory Activities
}

\author{
BEVERLY ERREDE, ${ }^{1 *}$ MAHSHID COMPANY,${ }^{1}$ AND CLYDE A. HUTCHISON III $^{2}$ \\ Department of Chemistry, ${ }^{1}$ and Department of Microbiology and Immunology, ${ }^{2}$ University of North Carolina, \\ Chapel Hill, North Carolina 27514
}

Received 10 July 1986/Accepted 16 September 1986

\begin{abstract}
Some insertion mutations in Saccharomyces cerevisiae activate the expression of adjacent structural genes. The CYC7-H2 mutation is a Ty1 insertion $5^{\prime}$ to the iso-2-cytochrome coding region of CYC7. The Ty1 insertion causes a 20-fold increase in CYC7 expression in a and $\alpha$ haploid cell types of $S$. cerevisiae. This activation is repressed in the a/ $\alpha$ diploid cell type. Previous computer analysis of the CYC7-H2 Ty1 activator region identified two related sequences with homology both to mammalian enhancers and to a yeast a/ $\alpha$ control site. A 112-base-pair (bp) DNA fragment encompassing one of these blocks of homology functioned as one component of the Ty1 activator. A 28-bp synthetic oligonucleotide with the wild-type homology block sequence was also functional. A single base pair mutation within the enhancer core of the synthetic 28-bp regulatory element reduced its activation ability to near background amounts. In addition, the 112-bp Ty1 fragment by itself functioned as a target for repression of adjacent gene expression in a/ $\alpha$ diploid cells.
\end{abstract}

Ty transposable elements are a dispersed repeated gene family in Saccharomyces cerevisiae (4). Ty elements are similar to proviral forms of vertebrate retroviruses in structure, transcriptional properties, and gene organization $(4,6$, $10,54)$. These similarities are extended by the findings that Ty elements transpose through an RNA intermediate, encode a reverse transcriptase, and produce viruslike particles $(2,19,34)$. Also similar to retroviruses, insertions of Ty can activate expression of cellular genes (for a review, see reference 56). In this capacity Ty elements exhibit enhancerlike properties. Enhancers are relatively position- and orientation-independent transcriptional control elements that are capable of activating transcription from heterologous promoters (21). Ty elements can activate transcription from positions 125 to 600 base pairs $(\mathrm{bp})$ upstream from the coding sequences of various genes $(13,16,27,29,37,46,57)$. The normal site of transcript initiation for the affected gene is used $(37,57)$. The orientation of Ty elements is such that the transcription unit for the element and the activated gene is divergent. Transcription of both $\mathrm{Ty}$ and the genes that it activates is regulated identically (see below). This observation suggests that the same sequences are involved in the transcription of Ty RNA and the adjacent gene. Such a condition would require that the regulatory sequences within Ty elements function independently of orientation.

The $\mathrm{CYC7}-\mathrm{H} 2$ mutation is one example of a Ty element insertion that activates gene expression. In this mutation a class I Ty element is inserted at the $C Y C 7$ locus between the coding sequence for iso-2-cytochrome $c$ and the normal upstream transcriptional control sequences $(13,16,29,58$, 59). The consequence is that Ty1 transcriptional control sequences regulate expression of $C Y C 7$. Ty RNA and genes under Ty control, including $C Y C 7-H 2$, are subject to matingtype controls $(9,11,13,44,53)$. One feature of mating-type specialization in $S$. cerevisiae is that haploid-specific gene expression is repressed in $\mathbf{a} / \alpha$ diploid cells (23). Similar to other haploid-specific genes, repression of Ty RNA and

\footnotetext{
* Corresponding author.
}

CYC7-H2 expression is dependent on the a1 and $\alpha 2$ regulatory proteins encoded at $M A T(11,13)$. The same regulatory determinants, in addition to those encoded at $M A T$, are required for expression of Ty RNA and Ty-controlled genes in both haploid cell-types of $S$. cerevisiae $(9,13,53)$.

The nucleotide sequence of the CYC7-H2 Ty1 control region was determined previously and analyzed for the presence of enhancer and mating-type responsive elements (15). Several short consensus sequences have been identified that are common to certain groups of enhancers. One example is the core consensus sequence, TGG AATG, that is common to the simian virus 40 (SV40) enhancer and several other viral and cellular enhancers $(21,22,30,55)$. Computer analysis identified two closely related sequences in the CYC7-H2 Ty1 with homology to the SV40 enhancer core region (Fig. 1). A 28-bp sequence in the $M A T \alpha$ intergenic region that mediates a1- $\alpha 2$ repression in diploid $S$. cerevisiae has been identified and characterized $(50,51)$. The two enhancerlike sequences identified in the CYC7-H2 Tyl overlap sequences with homology to the diploid control site at $M A T \alpha$ (Fig. 1). Results from restriction fragment deletions led us to predict that the homology blocks in Ty1 are necessary for cell-type-specific activation of $C Y C 7$ expression in the $\mathrm{CYC7}-\mathrm{H} 2$ mutation (15). Analysis of class II Ty elements inserted at the HIS4 locus has shown that sequences in the vicinity of homology to the SV40 enhancer are similarly important for $\mathrm{Ty}$ activation of the adjacent HIS4 gene (43).

\section{MATERIALS AND METHODS}

Chemical synthesis of DNA and cloning of synthetic DNA. Oligonucleotides described in these studies were synthesized on a DNA synthesizer (model 380A; Applied Biosystems). Two mutagenized oligonucleotides corresponding to each strand of the 28-bp Ty1 block II sequence were synthesized (Fig. 2). The two complementary, mutagenized oligonucleotides were annealed and inserted into the SalIBamHI sites of M13 mp11 replicative form (RF) DNA. Escherichia coli JM107 was transformed with the resulting population of recombinant phage to generate a library of 


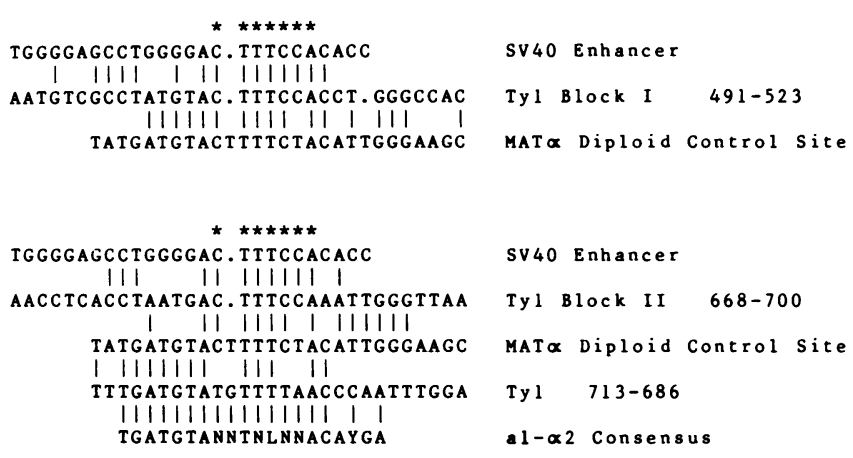

FIG. 1. Alignment of Ty1 sequences with SV40 and MATa regulatory sequences. Vertical lines indicate identical bases between two sequences on adjacent lines.Dots are inserted to maximize alignment. The SV40 sequence is 26 bp from the 72-bp repeat, which includes the seven-nucleotide enhancer core (55). Core sequences are indicated by asterisks. The MAT $\alpha$ sequence is the 28 -bp fragment which has been shown to be sufficient for repression of $M A T \alpha 1$ in diploid cells (51). The al- $\alpha 2$ consensus was deduced from the MAT $\alpha$ diploid control site and homologous regions from $\mathrm{HO}$ and STE5 (35). N represents any nucleotide, $\mathrm{L}$ represents $\mathrm{A}$ or $\mathrm{T}$, and $\mathrm{Y}$ represents $\mathrm{C}$ or $\mathrm{T}$. CYC7-H2 Ty1 sequences are from previously described data (15). Block I and block II refer to Tyl sequences with overlapping homology to the SV40 enhancer region and to the $M A T \alpha$ diploid control site. $S V 40, M A T \alpha$, al- $\alpha 2$ consensus, and Ty1 sequences 713 to 686 are the complement of the sequences presented previously $(15,35,51,55)$.

point substitution mutations throughout the synthesized interval. Procedures for the synthesis, cloning, and sequencing of the mutants have been provided previously in detail (25). Characterization of the mutant library is in progress, and its detailed description will be presented elsewhere. In this study we analyzed the phenotype of two isolates from the library; the wild type and one mutant with a single base substitution in the enhancer core. The Sall-BamHI fragments from the corresponding M13 RF DNA were cloned into the SalI-BamHI site of the $S$. cerevisiae-E. coli shuttle vector described below.

Plasmid constructions. $\mathrm{CYC7}-\mathrm{H} 2$ and $\mathrm{CYC7}^{+}$plasmids used in these studies were constructed from previously described centromeric plasmids designated pNC3 and pNC5, respectively (15). Both plasmids are derived from pYe(CEN3)-30 which is a pBR322-based vector with $S$. cerevisiae TRP1, ARS1, and CEN3 sequences (17). Plasmid DNA was prepared by the rapid boiling procedure (24). The crude plasmid DNA was treated with RNase, and protein was extracted with phenol. All enzymes used in the constructions were purchased either from New England Biolabs, Inc. (Beverly, Mass.) or U.S. Biochemicals (Cleveland, Ohio). Restriction digestions, DNA ligation reactions, and 3 '-end repair with T4 DNA polymerase were performed by standard procedures (33). The linker tailing method was used to attach linkers (31). BamHI and SalI linkers were purchased from New England Biolabs. All plasmid constructions were amplified by transformation into $E$. coli $\mathrm{HB} 101$ (3, 38). Each construction was verified by restriction endonuclease cleavage analysis. Junction regions were verified by DNA sequence analysis. Insertions into $C Y C 7$ sequences were verified by subcloning appropriate regions of plasmid DNA into M13. The DNA sequence was determined by the chain termination method by procedures described previously (1). Insertions into Ty1 sequences were verified by directly sequencing plasmid DNA (5). An oligonucleotide complementary to the region of interest was synthesized and used as the primer.

$S$. cerevisiae strains and genetic procedures. Complete genotypes for the $S$. cerevisiae strains used in this study are given in Table 1. All strains were iso-1-cytochrome $c$ deficient because of mutations at the $C Y C l$ structural gene. The

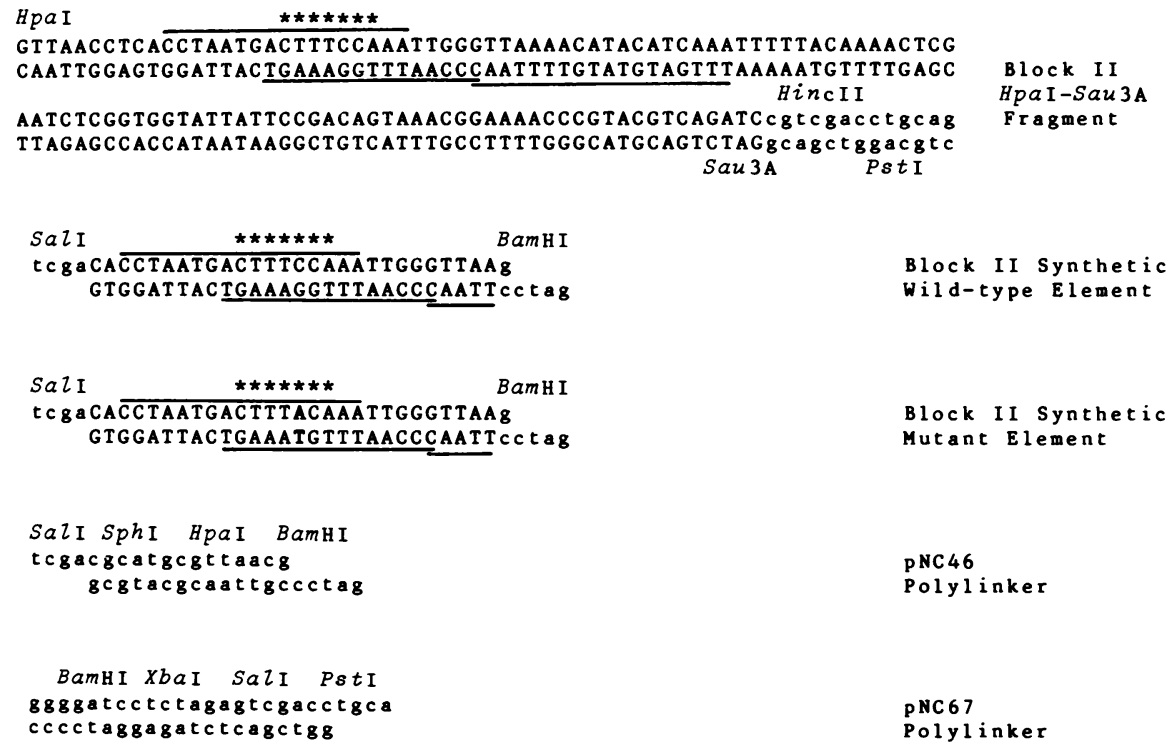

FIG. 2. Predicted Ty1 regulatory sequences and polylinker sequences. Ty1 sequences are indicated by capital letters and polylinker sequences are indicated by lowercase letters. The 112-bp Tyl Hpal-Sau3A fragment includes Ty1 sequence positions 668 to 779 (15). A Ty1 Sau3A fragment (positions 234 to 779) subcloned into the BamHI site of M13 mp8 was the source of the HpaI-Sau3A sequence for constructions described in this study. The overlined sequences are homologous to the SV40 enhancer region. Asterisks indicate the position of the seven-nucleotide enhancer core sequence. The underlined regions are homologous to the MATa diploid control site (see Fig. 1). The single base pair substitution mutation in the enhancer core region of the synthetic block II sequence is indicated by boldface letters. The symbols to the right are used in Fig. 3 to represent the corresponding sequences. 


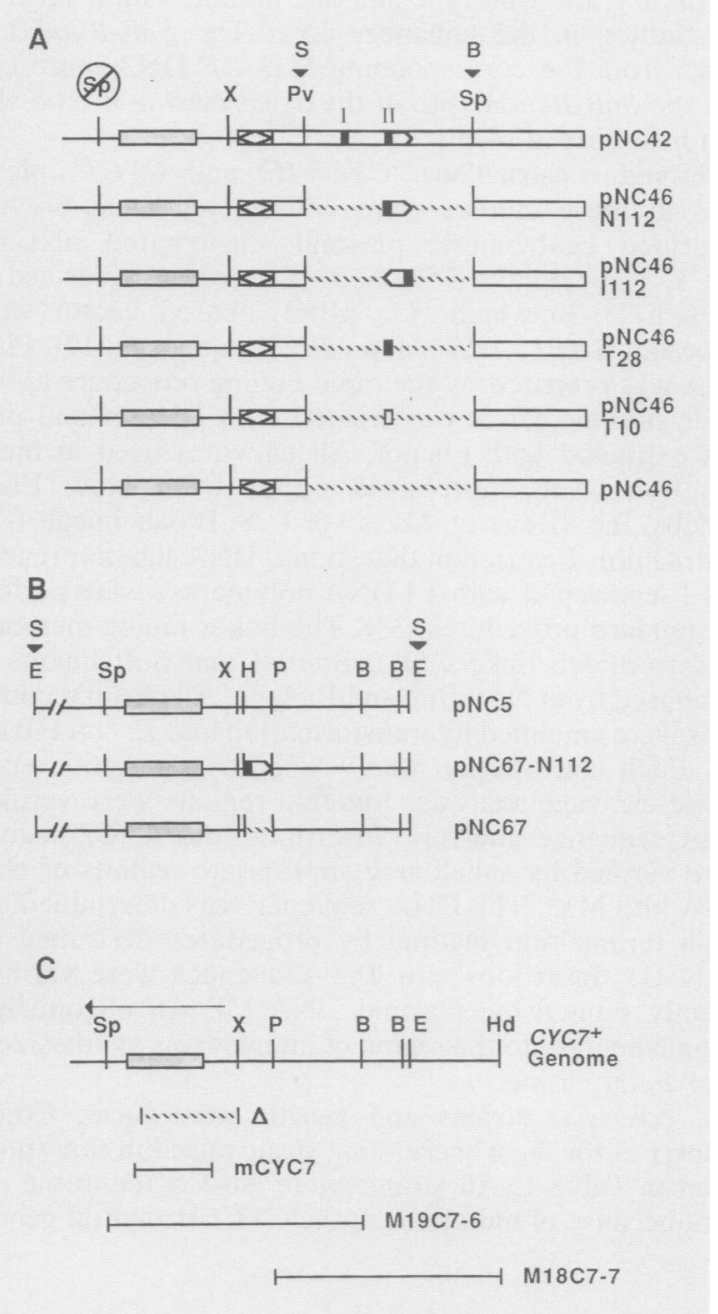

FIG. 3. (A) $\mathrm{CYC7}-\mathrm{H} 2$ region from pNC3-derived plasmids. The entire $C Y C 7$-coding region is present in all constructions and is represented by the shaded box. pNC3 includes $1.5 \mathrm{~kb}$ of Ty1 proximal to the CYC7-coding region. The open box represents Ty1 sequences. The delta region of Ty1 is indicated by a diamond. The block I and block II sequences within Ty1 are indicated by solid boxes labeled I and II, respectively. The 112-bp HpaI-Sau3A fragment includes block II and adjacent sequences delimited by the arrowhead. The solid box and the open box within the broken lines indicate, respectively, the synthetic wild-type and mutant block II elements. The sequences corresponding to the 112-bp block II fragment, the wild-type block II element, and the mutant block II element are given in Fig. 2. The broken lines indicate deleted sequences. The downward-pointing arrows indicate the positions of restriction site linker insertions. The leftmost $S p h \mathrm{I}$ site was destroyed by cleavage with $S p h \mathrm{I}$, end repair with T4 polymerase, and religation. (B) CYC7 region from pNC5-derived plasmids. Symbols in the diagrams are the same as those described above for panel A. Only the HaeIII site that forms the junction in pNC67 and pNC67$\mathrm{N} 112$ is shown. (C) $\mathrm{CYC7}^{+}$region on chromosome V. Symbols in the diagram are the same as those described above for panel A. The arrow above the $C Y C 7$-coding region indicates the direction and extent of $C Y C 7$ transcription. The broken bar below the diagram delimits the deleted sequences in the cyc7-67 allele. The solid bars below the diagram delimit the DNA probes used in Northern and Southern blot experiments. Restriction sites in panels $\mathrm{A}$ to $\mathrm{C}$ are abbreviated as follows: B, BamHI; E, EcoRI; H, HaeIII; Hd, HindIII; P, PstI; Pv, PvuII; S, SalI; Sp, SphI; X, XhoI.
TABLE 1. Yeast strains used in this study

\begin{tabular}{|c|c|}
\hline Strain & Genotype \\
\hline E906-8B & $\underset{52}{\text { MATa } c y c 1-11 \text { cyc7-67 canl leu2-3,-112 trpl- } \Delta 1 \text { ura3- }}$ \\
\hline $\begin{array}{l}\text { E730-4A } \\
\text { KZ8-5C }\end{array}$ & $\begin{array}{l}\text { MAT a cycl cyc7-67 canl his5 leu2 trpl } \\
\text { MATa cycl CYC7 }{ }^{+} \text {his } 4 \text { ural }\end{array}$ \\
\hline J14046-7A & MATa cycl $C Y C 7^{+}$cyc10-1 met14 lys1 lys 2 \\
\hline E378-1A & MATa cycl CYC7-H2 cryl hisl lys2 \\
\hline
\end{tabular}

cycl-11 allele in strain E906-8B is a 2-bp substitution that changes the CCA codon at iso-1-cytochrome $c$ amino acid position 76 to a TAA nonsense codon (12). Strains E906-8B and E730-4A were also iso-2-cytochrome $c$ deficient because of the cyc7-67 allele which is a CYC7 deletion (see Fig. 3C) described by T. Cardillo and $\mathrm{K}$. Zaret (cited in reference 14). The $\mathrm{CYC7}^{+}$strain $\mathrm{KZ8}-5 \mathrm{C}$, the cycl0 $\mathrm{CYC7}^{+}$strain J14046-7A, and the $C Y C 7-H 2$ strain E378-1A were used as standards for our comparisons of $C Y C 7$ expression. The cyc10 allele in J14046-7A caused a fourfold increase in the amount of iso-2-cytochrome $c$ produced compared with $\mathrm{CYClO}^{+} \mathrm{CYC7}^{+}$strains (29).

Media and conventional yeast genetic procedures for crosses, strain constructions, and scoring nutritional markers have been described by Sherman et al. (47). For the purpose of cytochrome $c$ or $C Y C 7 \mathrm{mRNA}$ determinations, strains were grown under derepressing conditions on YPS medium (1\% [wt/vol] yeast extract [Difco Laboratories, Detroit, Mich.] and 2\% [wt/vol] Bacto-Peptone [Difco], $1 \%$ [wt/vol] sucrose).

Yeast transformation. Two independent $E$. coli isolates for each construction were used to transform $S$. cerevisiae

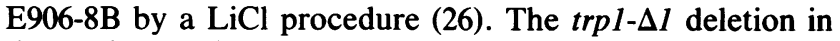
the strain permits selection of the pNC3- and pNC5-derived plasmids by requiring growth on synthetic medium lacking tryptophan.

Iso-2-cytochrome $c$ determinations. Derepressed cells for determination of cytochrome $c$ content were grown as narrow lines on solid YPS medium. Spectroscopic examination of intact cells at $-196^{\circ} \mathrm{C}$ was performed with a wavelength prism spectroscope (48). This method allows estimation of cytochrome $c$ content in transformed strains by comparing the intensities of the $c_{\alpha}$ bands with those for standard strains with known amounts of cytochrome $c$. Quantitative determinations of cytochrome $c$ content were also made by spectrophotometric examination of cytochrome $c$ extracted from $1.5 \mathrm{~g}$ (wet weight) of cells. Cell lysis, cytochrome $c$ extraction, and cytochrome $c$ isolation procedures were adapted from those of Sherman et al. (49). The total amount of cytochrome $c$ from each cell suspension was recovered in a final volume of $1 \mathrm{ml}$. The cytochrome $c$ solutions were reduced by the addition of a few crystals of sodium dithionite. The absorption spectra from 450 to $650 \mathrm{~nm}$ were measured on an diode array spectrophotometer (model 8450A; Hewlett-Packard Co., Palo Alto, Calif.). The concentration of the solution was calculated by using the value of $27.6 \mathrm{~cm}^{-1} \mathrm{mM}^{-1}$ for the reduced $c_{\alpha}$ band extinction coefficient at $550 \mathrm{~nm}(45)$.

Hybridization probes. The M13 recombinant phage mCYC7 was provided by D. Pietras and F. Sherman (32). The CYC7 fragments M19C7-6 and M18C7-7 (Fig. 3C) were subcloned and maintained in M13 mp19 and M13 mp18, respectively. The plasmid pYactI which contains the yeast actin gene ( $A C T 1)$ was provided by $\mathrm{R}$. $\mathrm{Ng}$ and $\mathrm{J}$. Abelson (39).

The $C Y C 7$ fragments shown in Fig. 3C were isolated from 
TABLE 2. Comparison of cytochrome $c$ produced by $C Y C 7^{+}$, $\mathrm{CYC7}-\mathrm{H} 2$, and $\mathrm{CYC}-\mathrm{H} 2$ derivative strains

\begin{tabular}{|c|c|c|c|c|}
\hline \multirow{3}{*}{ Allele(s) } & \multirow{3}{*}{ Plasmid } & \multicolumn{3}{|c|}{ Amt of cytochrome $c$ in ${ }^{a}$ : } \\
\hline & & \multirow{2}{*}{$\begin{array}{l}\text { intact cells } \\
\text { (relative) }^{b}\end{array}$} & \multicolumn{2}{|c|}{ Extracts } \\
\hline & & & $\overline{\text { nmol }^{c}}$ & Relative $^{d}$ \\
\hline CYC7-H2 & & $21 \pm 1.3$ & 8.9 & 22 \\
\hline $\mathrm{CYC7}^{+} \mathrm{cyclO}$ & & $5 \pm 1.6$ & 1.6 & 4 \\
\hline $\mathrm{CYC7}^{+}$ & & $1 \pm 0.3$ & 0.4 & 1 \\
\hline cyc7-67 & & 0 & & \\
\hline$c y c 7-67$ & pNC42 & $29 \pm 3.3$ & 14.0 & 35 \\
\hline cyc7-67 & pNC46 & $6 \pm 1.1$ & 3.2 & 8 \\
\hline cyc7-67 & pNC46-T10 & $7 \pm 1.7$ & 4.2 & 10 \\
\hline cyc7-67 & pNC46-T28 & $18 \pm 3.1$ & 6.1 & 15 \\
\hline cyc7-67 & pNC46-N112 & $20 \pm 1.4$ & 7.6 & 19 \\
\hline cyc7-67 & pNC46-I112 & $29 \pm 4.3$ & 10.4 & 26 \\
\hline
\end{tabular}

${ }^{a}$ Values are not corrected for plasmid copy number in each culture.

${ }^{b}$ Amounts of cytochrome $c$ are relative to the amount produced by a standard $\mathrm{CYC7}^{+}$strain. Twelve independent isolates were analyzed from each plasmid transformation. Values are the means \pm standard deviations.

${ }^{c}$ Results are the average of three independent extractions and determinations.

${ }^{d}$ Amounts are relative to the nanomoles of cytochrome $c$ extracted from the standard $C Y C 7^{+}$strain.

the corresponding RF DNAs and were used to prepare $C Y C 7$ DNA and mRNA hybridization probes. A 2.2-kilobase (kb) EcoRI-HindIII fragment isolated from pYactI was used to prepare an $A C T I$ mRNA hybridization probe. RF and plasmid DNAs for fragment isolations were prepared by a $\mathrm{CsCl}$ banding method (40). After digestion with appropriate restriction enzymes, double-stranded DNA fragments were isolated from agarose gels (8). Fragments were labeled with $\left[\alpha^{-32}\right.$ P]dCTP (New England Nuclear Corp., Boston, Mass.) by the nick-translation reaction described previously (42).

Yeast RNA preparation and Northern hybridization analysis. Yeast RNA preparation and Northern hybridization procedures were carried out as described previously (7). Filters were hybridized to radioactively labeled mCYC7 DNA to detect the 0.6-kb CYC7 mRNA. Hybridization to $A C T 1$ mRNA on the same filters provided an internal control for the loading and the transfer of RNA. Filters were boiled in water for $10 \mathrm{~min}$ to remove the $\mathrm{mCYC7}$ DNA probe and then were hybridized to radioactively labeled $A C T 1$ DNA. The $A C T 1$ probe that we used hybridizes to two yeast transcripts: the 1.25-kb actin RNA and another 0.66-kb RNA (18). A computer-interfaced laser densitometer (model 2202; LKB Instruments, Inc., Rockville, Md.) programmed to measure relative peak areas from bands on autoradiograms was used to measure the intensity of $C Y C 7$ and $A C T 1$ hybridizing bands.

Yeast DNA preparation and Southern hybridization analysis. Total yeast DNA was isolated essentially by procedures described previously (47). Restriction endonucleasedigested DNA samples were fractionated by electrophoresis and transferred to nitrocellulose (52). The filters were hybridized to radioactively labeled $C Y C 7$ DNA probes under previously described conditions (33). The relative amount of plasmid DNA from each culture was determined by the ratio of plasmid to genomic band intensities on autoradiograms, as measured by densitometry.

\section{RESULTS}

Analysis of the Ty1 block II sequence for enhancer function. The sequences designated block I and block II have homology to the MAT $\alpha$ diploid control site and to the SV40 enhancer (Fig. 1). The location of blocks I and II in Ty1 are shown in Fig. 3A. Tests were made to determine whether the block II region has enhancer activity. Deletion of the 744-bp $P v u I I-S p h I$ fragment that encompasses both blocks I and II abolishes the full activation effects of Ty1 on CYC7 expression. The strategy for our test was to replace the PvuII-SphI region of Ty1 with small segments of DNA that contain the putative regulatory sequence. The ability of the Ty1 derivatives to activate $C Y C 7$ expression was determined in $S$. cerevisiae on the basis of iso-2-cytochrome $c$ and $C Y C 7$ mRNA production.

Plasmids constructed for these analyses were each derived from the CYC7-H2 centromeric plasmid pNC3 (Fig. 3A). The $P v u I I$ and $S p h I$ restriction sites in the Ty1 region of pNC3 were modified by insertion of SalI and BamHI linkers, respectively, to give the plasmid designated pNC42. The restriction site alterations provided convenient cloning sites in the Ty1 sequence without affecting $C Y C 7-H 2$ expression. The SalI and BamHI fragment of pNC42 was replaced by different DNA fragments with sequences shown in Fig. 2. A synthetic polylinker was inserted between the cloning sites to give the deletion control plasmid designated pNC46. A 112-bp block II region of Tyl was transferred into the $\mathrm{HpaI}$ site of pNC46 as a HincII fragment from an appropriate M13 subclone. The construction with the fragment in its normal orientation is designated pNC46-N112, and the construction with the fragment in an inverted orientation is designated

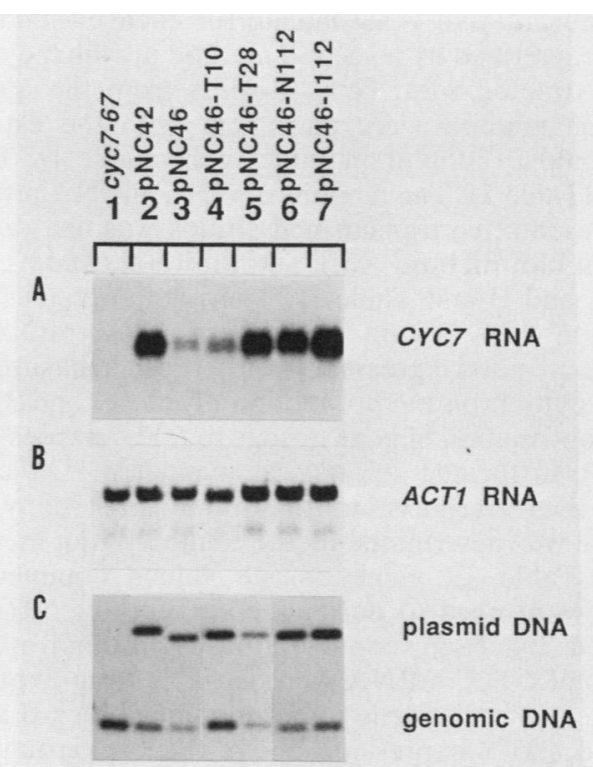

FIG. 4. (A) Autoradiogram of a Northern blot showing CYC7 mRNA. A total of $20 \mu \mathrm{g}$ of total RNA from the cyc7-67 recipient strain and strains with diferent plasmids were loaded into each lane, as indicated at the top of the figure. The filter was hybridized to the radiolabeled mCYC7 DNA probe diagrammed in Fig. 3. (B) Autoradiogram of a Northern blot showing $A C T 1$ mRNA. The filters shown in panel $A$ were washed and rehybridized to an actin DNA probe. The signal intensity for $A C T 1$ mRNA provides an internal control for the amount of RNA transferred to the filter. (C) Autoradiogram of a Southern blot comparing the amount of CYC7hybridizing plasmid and genomic DNA. Approximately $1 \mu \mathrm{g}$ of EcoRI-digested DNA from the cyc7-67 recipient strain and from strains with different plasmids were loaded into each lane, as indicated at the top of the figure. The filters were hybridized to the radiolabeled M19C7-6 DNA probe (Fig. 3). The bands corresponding to plasmid and genomic DNA are indicated to the right of the autoradiogram. 
TABLE 3. Comparison of $C Y C 7$ RNA produced from $C Y C 7-H 2$ and $C Y C 7-H 2$ derivative strains ${ }^{a}$

\begin{tabular}{|c|c|c|c|c|c|c|c|c|c|c|c|}
\hline \multirow{3}{*}{ Allele(s) } & \multirow{3}{*}{ Plasmid } & \multicolumn{6}{|c|}{ Expt 1} & \multicolumn{4}{|c|}{ Expt 2} \\
\hline & & \multicolumn{3}{|c|}{ Amt of $\mathrm{RNA}^{b}$} & \multirow{2}{*}{$\begin{array}{c}\text { Gene } \\
\text { dosage }^{c}\end{array}$} & \multicolumn{2}{|c|}{$\begin{array}{l}\text { Normalized } \\
\text { expression }\end{array}$} & \multicolumn{3}{|c|}{ Amt of $\mathrm{RNA}^{b}$} & \multirow{2}{*}{$\begin{array}{c}\text { Gene } \\
\text { dosage }^{c}\end{array}$} \\
\hline & & $C Y C 7$ & $A C T I$ & $\frac{C Y C 7}{A C T 1}$ & & Per gene $e^{e}$ & Relative $^{f}$ & $C Y C 7$ & $A C T I$ & $\frac{C Y C 7}{A C T 1}$ & \\
\hline CYC7-H2 & & & & & & & & 4,406 & 3,453 & 1.3 & 1 \\
\hline $\mathrm{CYC7}^{+} \mathrm{cycl0}$ & & & & & & & & 569 & 2,531 & 0.2 & 1 \\
\hline cyc7-67 & & 0 & 748 & 0 & 1 & 0 & 0 & & & & \\
\hline cyc7-67 & pNC42 & 2,816 & 863 & 3.3 & 2.2 & 1.5 & 8 & 6,661 & 2,029 & 3.3 & 1.9 \\
\hline cyc7-67 & pNC46 & 336 & 662 & 0.5 & 2.6 & 0.2 & 1 & 700 & 1,506 & 0.5 & 2.5 \\
\hline cyc7-67 & pNC46-T10 & 389 & 745 & 0.5 & 1.2 & 0.4 & 2 & 947 & 1,260 & 0.8 & 1.3 \\
\hline cyc7-67 & pNC46-T28 & 2,867 & 1,373 & 2.1 & 1.7 & 1.2 & 6 & 3,541 & 1,424 & 2.5 & 1.5 \\
\hline cyc7-67 & pNC46-N112 & 2,423 & 1,349 & 1.8 & 2.5 & 0.7 & 4 & 3,878 & 1,883 & 2.1 & 2.6 \\
\hline cyc7-67 & pNC46-I112 & 7,375 & 1,637 & 4.5 & 2.3 & 2.0 & 10 & 6,435 & 1,703 & 3.8 & 3.2 \\
\hline
\end{tabular}

pNC46-I112. A synthetic oligonucleotide with $28 \mathrm{bp}$ of sequence corresponding to block II and an oliognucleotide with a single base substitution in the enhancer core sequence of block II were cloned in the SalI and BamHI sites of pNC46. The resulting derivatives are designated pNC46-T28 and pNC46-T10, respectively.

Each plasmid was used to transform cytochrome $c$ deficient $S$. cerevisiae E906-8B. Spectroscopic examination of intact transformed cells showed that each construction produced a characteristic amount of cytochrome $c$ (Table 2). One representative yeast isolate for each plasmid was further characterized by a second method in which cytochrome $c$ was extracted from cells. Results from the quantitative extraction method were consistent with the estimates of cytochrome $c$ content in intact cells made by the visual method (Table 2). The amount of $C Y C 7$ mRNA produced by the representative transformed strains was analyzed by the Northern blot method, with actin mRNA used as a control (Fig. 4A and $\mathrm{B}$ and Table 3). The relative values of $\mathrm{CYC7}$ expression measured on the basis of $C Y C 7 \mathrm{mRNA}$ productionwere in good agreement with those measured on the basis of cytochrome $c$ production (Tables 2 and 3 ).

The contribution of gene dosage to $C Y C 7$ expression in the various transformed strains was evaluated. The amount of plasmid DNA relative to that of a single-copy genomic sequence was determined by the Southern blot method (Fig. 4C and Table 3). Gene dosage values obtained by this method were used to normalize amounts of $C Y C 7$ mRNA produced by each construction. Although normalized amounts of $C Y C 7$ mRNA were variable from experiment to experiment, the constructions containing block II sequences activated $C Y C 7$ expression above the background amount observed with pNC46. Also, in each experiment the amount of $C Y C 7$ mRNA associated with the mutant block II sequence was less than that observed with the wild-type sequence. The following conclusions are drawn from the average relative expression determined for each plasmid shown in Table 3. (i) Deletion of the 744-bp fragment from Tyl resulted in a sevenfold reduction in $C Y C 7$ expression for the pNC46 deletion plasmid compared with the pNC42 CYC7-H2 plasmid. (ii) Insertion of a 112-bp restriction fragment encompassing block II into pNC46 in the normal orientation (pNC46-N112) restored CYC7 activation to an amount that was fourfold above that of the background. (iii) The 112-bp restriction fragment inserted in the inverted orientation (pNC46-I112) restored activation to amounts near that observed for the $C Y C 7-H 2$ plasmid pNC42. (iv) The 28-bp synthetic block II element (pNC46-T28) similarly caused a sixfold activation above that of the background. This result defines the 28-bp block II sequence as one component of the Ty1 activator. (v) A single base pair mutation in the enhancer core of the block II sequence (pNC46-T10) reduced the activation effect of block II to twofold above that of the background. This result demonstrates that the enhancer core sequence is essential for block II activator function.

Analysis of the block II region for diploid control function. The Ty1 sequence in pNC42 has seven sequences with homology to the diploid control site at MAT $\alpha$. Three of these potential targets of a1- $\alpha 2$ repression are present outside of the 744-bp fragment encompassing blocks I and II (15). For this reason the constructions used to analyze activator function of the block II sequence were not considered to be appropriate for evaluation of its diploid control function. To address this question, the 112-bp Ty1 fragment encompassing the block II sequence was tested for its effect on $C Y C 7$ gene expression in the absence of other Ty1 sequences.

Two plasmids constructed for these analyses were derived from the $\mathrm{CYC7}^{+}$plasmid pNC5 (Fig. 3B). In the control plasmid pNC67, a 90-bp HaeIII-PstI fragment of CYC7 was replaced by the M13 mp8 SmaI-PstI polylinker (Fig. 2). In pNC67-N112 the 90-bp CYC7 fragment was replaced by the Ty1 block II region isolated as a HpaI-PstI fragment from an appropriate M13 subclone (Fig. 2). The deleted CYC7 segment in both constructions is between positions -200 and -290 of the reported $C Y C 7$ nucleotide sequence (37). These sequences are required for the function of both the positive and negative transcriptional control elements identified at CYC7 (58, 59). Also note that the block II insertion in pNC67-N112 is only $16 \mathrm{bp}$ distal to the insertion junction for Ty1 in the CYC7-H2 mutation $(17,29)$.

We first determined whether the 112-bp Ty1 fragment could activate $C Y C 7$ gene expression by transformation of the constructions described above into haploid strain E906-8B. Transformed strains were analyzed for cytochrome $c$ production in intact cells as described above (data not shown). Table 4 shows the amounts of cytochrome $c$ extracted from representative isolates. The relative gene dosage contributed by the various plasmids in transformed strains was estimated as described above. The normalized amounts of iso-2-cytochrome $c$ for the $\mathrm{CYC7}^{+}$plasmid and the two derivatives were essentially the same (Table 4). We conclude that the 112-bp Ty1 fragment has no activator ability by itself.

We determined whether the basal $C Y C 7$ expression could be repressed in diploid yeast cells by the presence of the 
TABLE 3-Continued

\begin{tabular}{|c|c|c|c|c|c|c|c|c|c|c|c|}
\hline & & \multicolumn{6}{|c|}{ Expt 3} & \multirow{2}{*}{\multicolumn{3}{|c|}{$\begin{array}{l}\text { Normalized relative } \\
\text { expression in expt: }\end{array}$}} & \multirow{3}{*}{$\begin{array}{l}\text { Avg relative } \\
\text { expression }^{d}\end{array}$} \\
\hline \multicolumn{2}{|c|}{$\begin{array}{l}\text { Normalized } \\
\text { expression }\end{array}$} & \multicolumn{3}{|c|}{ Amt of $\mathrm{RNA}^{b}$} & \multirow{2}{*}{$\begin{array}{c}\text { Gene } \\
\text { dosage }^{c}\end{array}$} & \multicolumn{2}{|c|}{$\begin{array}{l}\text { Normalized } \\
\text { expression }\end{array}$} & & & & \\
\hline Per gene ${ }^{e}$ & Relative $^{f}$ & $C Y C 7$ & $A T C l$ & $\frac{C Y C 7}{\text { ACT1 }}$ & & Per gene & Relative $^{f}$ & 4 & 5 & 6 & \\
\hline 1.3 & 7 & 766 & 750 & 1.0 & 1 & 1.0 & 4 & & & & 5 \\
\hline 0.2 & 1 & 425 & 2,238 & 0.2 & 1 & 0.2 & 1 & & & 1 & $\begin{array}{l}1 \\
0\end{array}$ \\
\hline 1.7 & 9 & 2,630 & 2,544 & 1.0 & 0.9 & 1.1 & 4 & 9 & 4 & 6 & 7 \\
\hline 0.2 & 1 & 615 & 1,708 & 0.4 & 1.2 & 0.3 & 1 & 1 & 1 & & 1 \\
\hline 0.6 & 3 & 737 & 3,108 & 0.2 & 0.9 & 0.2 & 1 & 3 & 2 & 2 & 2 \\
\hline 1.7 & 9 & 2,076 & 2,015 & 1.0 & 1.3 & 0.8 & 3 & 9 & 3 & 5 & 6 \\
\hline 0.8 & 4 & & & & & & & 5 & & & 4 \\
\hline 1.2 & 6 & & & & & & & 5 & & & 7 \\
\hline
\end{tabular}

${ }^{a}$ Complete data are presented for three experiments that represent the range of relative expression observed for these comparisons. Relative expressions calculated from three additional experiments are also given. Results from independent Northern and Southern blots with the same preparations are presented in experiments 2 and 4 and in experiments 3 and 5 .

$b$ Values are integrated peak areas measured from autoradiograms by laser densitometry.

${ }^{c}$ Gene dosage is the ratio of $C Y C 7$ plasmid copy number to a single $C Y C 7$ genome copy in each culture. The value is obtained from integrated peak areas for the corresponding bands on autoradiograms measured by laser densitometry. The ratio is corrected for the amount of plasmid and genome homology to the radiolabeled M19C7-6 probe.

${ }^{d}$ The average is calculated from the relative expression values from experiments 1 to 6 .

e Normalized expression per gene is the CYC7/ACT1 value divided by the corresponding gene dosage for each culture.

$f$ Values are relative to the pNC46 control plasmid in experiments 1 to 5 and to the $C Y C 7^{+} c y c 10$ control in experiment 6 .

112-bp block II fragment. Tester strain E730-4A (MAT $\alpha)$ was crossed to representative transformed strains (MATa) and to the $C Y C 7-H 2$ strain E378-1A for reference. MAT $\alpha / M A T a$ diploid strains were isolated on the basis of complementing nutritional markers. Amounts of iso-2-cytochrome $c$ and relative gene dosage were determined as described above (Table 4). The plasmid with the 112-bp Ty1 fragment inserted upstream from the $C Y C 7$ coding region (pNC67-N112) produced approximately fivefold less iso-2-cytochrome $c$ in diploid cells than in haploid cells. Although the repression in diploid cells was not as large as that for the $\mathrm{CYC7}-\mathrm{H} 2$ allele in its chromosomal location, the repression was the same as that observed for pNC42, the $C Y C 7-H 2$ plasmid in these experiments. No repression was observed for the pNC5 or pNC67 control plasmids. These results indicate that the 112-bp fragment contains a functional target for diploid repression.

\section{DISCUSSION}

Ty1 homology block II functions as an enhancer of CYC7 expression when present with other Tyl sequences. A 744-bp Ty1 PvuII-SphI fragment, which is required for full activa- tion effects of Tyl on adjacent gene expression, includes two closely related sequences, designated block I and block II. Each block shows homology to both the SV40 enhancer and the diploid control site at MAT $\alpha$ (Fig. 1). In this report we showed that a synthetic 28-bp block II sequence could replace the 744-bp Ty1 region for the activation of adjacent CYC7 expression. A single base pair substitution within the enhancer core of the synthetic block II element reduced its activation ability to near background amounts. Hence, the activation of $C Y C 7$ expression that we observed with the block II element is sequence specific, and the enhancer core sequence is essential for its function. These results demonstrate that the block II sequence is a key component of the Ty activator.

In addition to the synthetic regulatory element, we analyzed a 112-bp Ty1 restriction fragment that included the block II sequence. The position of the block II sequence with respect to other Ty1 sequences in the constructions compared here is different from that in the parental Tyl element. The positional flexibility for the function of the block II region is characteristic of enhancer elements. We also showed that the 112-bp block II fragment functions in an inverted orientation so that it is similar to other enhancerlike

TABLE 4. Comparison of cytochrome $c$ produced from $\mathrm{CYC7-H2}, \mathrm{CYC7}^{+}$, and $\mathrm{CYC7}^{+}$derivative alleles

\begin{tabular}{|c|c|c|c|c|c|c|c|c|}
\hline \multirow[b]{2}{*}{ Allele } & \multirow[b]{2}{*}{ Plasmid } & \multicolumn{3}{|c|}{ Haploid cell type } & \multicolumn{3}{|c|}{ Diploid cell type } & \multirow[b]{2}{*}{$\begin{array}{l}\text { Fold } \\
\text { repression }^{d}\end{array}$} \\
\hline & & $\begin{array}{c}\text { Cytochrome } \\
c \\
(\mathrm{nmol})^{a}\end{array}$ & $\begin{array}{c}\text { Gene } \\
\text { dosage }^{b}\end{array}$ & $\begin{array}{l}\text { Normalized } \\
\text { expression }^{c}\end{array}$ & $\begin{array}{c}\text { Cytochrome } \\
\cdot c \\
(\mathrm{nmol})^{a}\end{array}$ & $\begin{array}{c}\text { Gene } \\
\text { dosage }^{b}\end{array}$ & $\begin{array}{l}\text { Normalized } \\
\text { expression }^{c}\end{array}$ & \\
\hline CYC7-H2 & & 9.9 & 1 & 9.9 & 0.4 & 0.5 & 0.8 & 12.4 \\
\hline cyc7-67 & pNC42 & 15.7 & 1.4 & 11.2 & 4.3 & 1.8 & 2.4 & 4.7 \\
\hline cyc7-67 & pNC5 & 2.0 & 3.1 & 0.6 & 1.1 & 1.2 & 0.9 & 0.7 \\
\hline cyc7-67 & pNC67 & 2.1 & 3.0 & 0.7 & 1.3 & 1.9 & 0.7 & 1.0 \\
\hline cyc7-67 & pNC67-N112 & 3.1 & 2.2 & 1.4 & 0.4 & 1.2 & 0.3 & 4.7 \\
\hline
\end{tabular}

${ }^{a}$ Values shown are the average of two independent extractions and determinations.

${ }^{b}$ Gene dosage is the ratio of $C Y C 7$ plasmid copy to $C Y C 7$ genome copy in each culture. The value is obtained from integrated peak areas for the corresponding bands on autoradiograms measured by laser densitometry. The ratio is corrected for the amount of plasmid and genome homology to the radiolabeled M18C7-7 probe.

c Normalized expression is the nanomoles of cytochrome $c$ divided by the corresponding gene dosage for each culture.

${ }^{d}$ Fold repression is the normalized expression in the haploid cell type divided by the normalized expression in the diploid cell type. 
sequences in that it is orientation independent. All Ty insertion mutations characterized to date that activate adjacent gene expression, however, have the same orientation. It may be that the Ty enhancer sequences do not operate over the distance found in the case of an inverted element or that some other component of the Ty activator is orientation dependent.

Several observations suggest that the Ty1 activator has a multicomponent structure. First, the block II sequence functioned as an activator of $C Y C 7$ expression in the presence of other Ty1 sequences. No significant activation of CYC7 expression was observed, however, when the 112-bp block II fragment by itself was inserted upstream of the CYC7-coding region. Second, deletions involving various sequences outside of the block I and II regions of Ty1 have a deleterious effect on $\mathrm{CYC7}-\mathrm{H} 2$ expression (M. Company, unpublished data). Third, Roeder et al. (43) have shown by analysis of mutant derivatives of a Ty insertion at HIS4 that sequences in addition to the enhancerlike region are essential for the activation of adjacent gene expression. A multicomponent structure is suggested from analyses of other enhancer regions such as those from SV40, the immunoglobulin $\kappa$ chain gene and the major histocompatibility complex $E_{\beta}$ gene $(20,22,41)$.

The 112-bp block II region includes a functional diploid control site. In diploid cells producing a1 and $\alpha 2$ regulatory proteins, $H O$ and $M A T \alpha l$ gene expression is reduced to below detectable amounts $(28,50)$. By contrast, the expression of Ty1, CYC7-H2, and RMEI is reduced only 5- to 20 -fold $(11,13,36)$. Nonidentical but closely related DNA sequences appear to mediate the quantitatively different response to a1- $\alpha 2$ repression observed for these various yeast genes. Siliciano and Tatchell $(50,51)$ have identified a single 28-bp sequence in the $M A T \alpha$ intergenic region that is sufficient to completely repress $M A T \alpha$ transcription. Multiple sites with homology to the $M A T \alpha$ diploid control site are found in Ty, HO, and STE5 $(15,35,44 \mathrm{a})$.

$C Y C 7$ expression was found to be $\sim$ fivefold lower in a/ $\alpha$ diploid cells than in haploid cells when the 112-bp block II fragment was inserted upstream of the $C Y C 7$-coding region. Although repression was less than that observed for CYC7$\mathrm{H} 2$ in its chromosomal location, the same fivefold repression was observed for a $\mathrm{CYC7}-\mathrm{H} 2$ centromeric plasmid analyzed in parallel studies. We conclude that the 112-bp Ty1 block II fragment encompasses a functional diploid control sequence. This Ty1 fragment contains two sequences that match the 28-bp MAT $\alpha$ diploid control sequence. The two sites have opposite orientations and are at positions 674 to 700 and 686 to 713 in the CYC7-H2 Ty1 sequence (Fig. 1). We note that the Ty1 homology site at positions 686 to 713 conforms more closely to the a1- $\alpha 2$ consensus sequence deduced from comparison of $M A T \alpha, H O$, and STE5 sequences (35). Additional experiments, however, will be necessary to determine whether the composite sequence or one or both of the homology sites constitutes the functional diploid control site of the 112-bp fragment.

A number of viral and cellular enhancers exhibit host or tissue specificitiy (21). Ty1 similarly exhibits cell-type specificitiy in its ability to activate adjacent gene expression. Results of this study demonstrate that the block II region of Ty1 contains both enhancer and diploid control activities. Although results of this study do not indicate whether or how this region might function within the context of Ty1, the implication is that the contiguous enhancerlike element and diploid control site(s) mediate cell-type specificitiy of the Ty1 activator.

\section{ACKNOWLEDGMENTS}

We thank Deborah Chaleff for critical reading of the manuscript. This research was supported by Public Health Service grants GM-30619 and AI-08998 from the National Institutes of Health.

\section{LITERATURE CITED}

1. Bankier, A. T., and B. G. Barrell. 1983. Shotgun DNA sequencing, p. 1-34. In R. A. Flavell (ed.), Techniques in nucleic acid biochemistry, vol. B5. Elsevier Scientific, Limerick, Ireland.

2. Boeke, J. D., D. J. Garfinkel, C. A. Styles, and G. R. Fink. 1985. Ty elements transpose through an RNA intermediate. Cell 40:491-500.

3. Boyer, H. W., and D. Roulland-Dussoix. 1969. A complementation analysis of the restriction and modification of DNA in Escherichia coli. J. Mol. Biol. 41:459-472.

4. Cameron, J. R., E. Y. Loh, and R. W. Davis. 1979. Evidence for transposition of dispersed repetitive DNA families in yeast. Cell 16:739-751.

5. Chen, E. Y., and P. H. Seeburg. 1985. Supercoil sequencing: a fast and simple method for sequencing plasmid DNA. DNA $4: 165-170$.

6. Clare, J., and P. Farabaugh. 1985. Nucleotide sequence of a yeast Ty element: evidence for a novel mechanism of gene expression. Proc. Natl. Acad. Sci. USA 82:2829-2833.

7. Company, M., and B. Errede. 1986. Transcriptional analysis of Ty1 deletion and inversion derivatives at CYC7. Mol. Cell. Biol. 6:3299-3311.

8. Dretzen, G., M. Bellard, P. Sassone-Corsi, and P. Chambon. 1981. A reliable method for the recovery of DNA fragments from agarose and acrylamide gels. Anal. Biochem. 112:295-298.

9. Dubois, E., E. Jacobs, and J. C. Jauniaux. 1982. Expression of the ROAM mutations in Saccharomyces cerevisiae: involvement of trans-acting regulatory elements and relation with the Ty1 transcription. EMBO J. 1:1133-1140.

10. Elder, R. T., E. Y. Loh, and R. W. Davis. 1983. RNA from the yeast transposable element Tyl has both ends in the direct repeats, a structure similar to retrovirus RNA. Proc. Natl. Acad. Sci. USA 80:2432-2436.

11. Elder, R. T., T. P. St. John, D. T. Stinchcomb, and R. W. Davis. 1981. RNA homologous to Ty1. Cold Spring Harbor Symp. Quant. Biol. 45:581-584.

12. Ernst, J. F., J. W. Stewart, and F. Sherman. 1981. The cyc1-11 mutation in yeast reverts by recombination with a nonallelic gene: composite genes determining iso-cytochromes $c$. Proc. Natl. Acad. Sci. USA 78:6334-6338.

13. Errede, B., T. S. Cardillo, F. Sherman, E. Dubois, J. Deschamps, and J. M. Wiame. 1980. Mating signals control expression of mutations resulting from insertion of a transposable repetitive element adjacent to diverse yeast genes. Cell 22:427-436.

14. Errede, B., T. S. Cardillo, M. A. Teague, and F. Sherman. 1984. Identification of regulatory regions within the Ty1 transposable element that regulate iso-2-cytochrome $c$ production in the CYC7-H2 yeast mutant. Mol. Cell. Biol. 4:1393-1401.

15. Errede, B., M. Company, J. D. Ferchak, C. A. Hutchison III, and W. S. Yarnell. 1985. Activation regions in a yeast transposon have homology to mating type control sequences and to mammalian enhancers. Proc. Natl. Acad. Sci. USA 82: 5423-5427.

16. Errede, B., M. Company, and R. Swanstrom. 1986. An anamolous Ty1 structure attributed to an error in reverse transcription. Mol. Cell. Biol. 6:1334-1338.

17. Fitzgerald-Hayes, M., L. Clarke, and J. Carbon. 1982. Nucleotide sequence comparisons and functional analysis of yeast centromere DNAs. Cell 29:235-244.

18. Gallwitz, D., and R. Seidel. 1980. Molecular cloning of the actin gene from yeast Saccharomyces cerevisiae. Nucleic Acids Res. 8:1043-1059.

19. Garfinkel, D. J., J. D. Boeke, and G. R. Fink. 1985. Ty element transposition: reverse transcriptase and virus-like particles. Cell 42:507-517.

20. Gillies, S. D., V. Folsom, and S. Tonegawa. 1984. Cell typespecific enhancer element associated with a mouse MHC gene, $\mathrm{E}_{\beta}$. Nature (London) 310:594-597. 
21. Gruss, P. 1984. Magic enhancers. DNA 3:1-5.

22. Herr, W., and J. Clarke. 1986. The SV40 enhancer is composed of multiple functional elements that can compensate for one another. Cell 45:461-470.

23. Herskowitz, I. 1986. Specialized cell types in yeast: their use in addressing problems in cell biology. UCLA Symp. Mol. Cell. Biol., p. 625-656.

24. Holmes, D. S., and M. Quigley. 1981. A rapid boiling method for the preparation of bacterial plasmids. Anal. Biochem. 114: 193-197.

25. Hutchison, C. A., III, S. K. Nordeen, K. Vogt, and M. H. Edgell. 1986. A complete library of point substitution mutations in the glucocorticoid response element of mouse mammary tumor virus. Proc. Natl. Acad. Sci. USA 83:710-714.

26. Ito, H., Y. Fukuda, K. Murata, and A. Kimura. 1983. Transformation of intact yeast cells treated with alkali cations. J. Bacteriol. 153:163-168.

27. Jauniaux, J. C., E. Dubois, S. Vissers, M. Crabeel, and J. Wiame. 1982. Molecular cloning, DNA structure and RNA analysis of the arginase gene in Saccharomyces cerevisiae. A study of cis-dominant regulatory mutations. EMBO J. 1:1125-1132.

28. Jensen, R., G. F. Sprague, Jr., and I. Herskowitz. 1983. Regulation of yeast mating-type interconversion: feedback control of HO gene expression by the mating-type locus. Proc. Natl. Acad. Sci. USA 80:3035-3039.

29. Kosiba, B. E., B. Errede, T. S. Cardillo, and F. Sherman. 1982. Mutants of yeast overproducing iso-2-cytochrome $c$. Recent Adv. Yeast Mol. Biol. 1:156-172.

30. Laimins, L. A.; M. Kessel, N. Rosenthal, and G. Khoury. 1983. Viral and cellular enhancer elements, p. 28-37. In Y. Gluzman, and T. Shenk (ed.) Current communications in molecular biology. Enhancers and eukaryotic gene expression. Cold Spring Harbor Laboratory, Cold Spring Harbor, N.Y.

31. Lathe, R., M. P. Kieny, S. Skory, and J. P. Lecocq. 1984. Linker tailing: unphosphorylated linker oligonucleotides for joining DNA termini. DNA 3:173-182.

32. Laz, T. M., D. F. Pietras, and F. Sherman. 1984. Differential regulation of the duplicated isocytochrome $c$ genes in yeast. Proc. Natl. Acad. Sci. USA 81:4475-4479.

33. Maniatis, T., E. F. Fritsch, and J. Sambrook. 1982. Molecular cloning: a laboratory manual. Cold Spring Harbor Laboratory, Cold Spring Harbor, N.Y.

34. Mellor, J., M. H. Malin, K. Gull, M. F. Tuite, S. McCready, T. Dibbayawan, S. M. Kingsman, and A. J. Kingsman. 1985. Reverse transcriptase activity and Ty RNA are associated with virus-like particles in yeast. Nature (London) 318:583-586.

35. Miller, A. M., V. L. MacKay, and K. A. Nasmyth. 1985. Identification and comparison of two sequence elements that confer cell-type specific transcription in yeast. Nature (London) 314:598-603.

36. Mitchell, A. P., and I. Herskowitz. 1986. Activation of meiosis and sporulation by repression of the $R M E 1$ product in yeast. Nature (London) 319:738-742.

37. Montgomery, D. L., J. M. Boss, S. J. McAndrew, L. Marr, D. A. Walthall, and R. Zitomer. 1982. The molecular characterization of three transcriptional mutations in the yeast iso-2-cytochrome $c$ gene. J. Biol. Chem. 257:7756-7761.

38. Morrison, D. A. 1977. Transformation in Escherichia coli: cryogenic preservation of competent cells. J. Bacteriol. 132: 349-351.

39. $\mathrm{Ng}, \mathrm{R}$., and $\mathrm{J}$. Abelson. 1980. Isolation and sequence of the gene for actin in Saccharomyces cerevisiae. Proc. Natl. Acad. Sci. USA 77:3912-3916.

40. Norgard, M. V. 1981. Rapid and simple removal of contaminat- ing RNA from plasmid DNA without use of RNase. Anal. Biochem. 113:34-42.

41. Picard, D., and W. Schaffiner. 1984. A lymphocyte-specific enhancer in the mouse immunoglobulin $\kappa$ gene. Nature (London) 307:80-82.

42. Rigby, P. W. J., M. Dieckmann, C. Rhodes, and P. Berg. 1977. Labeling deoxyribonucleic acid to high specific activity in vitro by nick translation with DNA polymerase I. J. Mol. Biol. 113:237-251.

43. Roeder, G. S., A. B. Rose, and R. E. Pearlman. 1985. Transposable element sequences involved in the enhancement of yeast gene expression. Proc. Natl. Acad. Sci. USA 82:5428-5432.

44. Rothstein, R. J., and F. Sherman. 1980. Dependence on mating type for the overproduction of iso-2-cytochrome $c$ in the yeast mutant CYC7-H2. Genetics 94:891-898.

44a.Russell, D. W., R. Jensen, M. J. Zoller, J. Burke, B. Errede, M. Smith, and I. Herskowitz. 1986. Structure of the Saccharomyces cerevisiae $\mathrm{HO}$ gene and analysis of its upstream regulatory region. Mol. Cell. Biol. 6:4281-4294.

45. Schejter, A., S. C. Glauser, P.George, and E. Margoliash. 1963. Spectra of cytochrome $c$ monomer and polymers. Biochim. Biophys. Acta 73:641-643.

46. Scherer, S., C. Mann, and R. W. Davis. 1982. Reversion of a promoter deletion in yeast. Nature (London) 298:815-819.

47. Sherman, F., G. R. Fink, and J. B. Hicks. 1983. Methods in yeast genetics: a laboratory manual. Cold Spring Harbor Laboratory, Cold Spring Harbor, N.Y.

48. Sherman, F., and P. P. Slonimski. 1964. Respiration-deficient mutants of yeast. II. Biochemistry. Biochim. Biophys. Acta 90:1-15.

49. Sherman, F., H. Taber, and W. Campbell. 1965. Genetic determination of iso-cytochromes $c$ in yeast. J. Mol. Biol. 13:21-39.

50. Siliciano, P. G., and K. Tatchell. 1984. Transcription and regulatory signals at the mating type locus in yeast. Cell 37:969-978.

51. Siliciano, P. G., and K. Tatchell. 1986. Identification of the DNA sequences controlling expression of the MAT $\alpha$ locus of yeast. Proc. Natl. Acad. Sci. USA 83:2320-2324.

52. Southern, E. M. 1975. Detection of specific sequences among DNA fragments separated by gel electrophoresis. J. Mol. Biol. 98:503-517.

53. Taguchi, A. K. W., M. Ciriacy, and E. T. Young. 1983. a/ $\alpha-$ suppression of alcohol dehydrogenase II expression in transposable element-associated mutants. Mol. Cell. Biol. 4:61-68.

54. Warmington, J. R., R. B. Waring, C. S. Newlon, K. J. Indge, and S. G. Oliver. 1985. Nucleotide sequence characterization of Ty1-17, a class II transposon from yeast. Nucleic Acids Res. 13:6679-6693.

55. Weiher, H., M. König, and P. Gruss. 1983. Multiple point mutations affecting the simian virus 40 enhancer. Science 219:626-631.

56. Williamson, V. M. 1983. Transposable elements in yeast. Int. Rev. Cytol. 83:1-25.

57. Williamson, V. M., D. Cox, E. T. Young, D. W. Russell, and M. Smith. 1983. Characterization of transposable elementassociated mutations that alter yeast alcohol dehydrogenase II expression. Mol. Cell. Biol. 3:20-31.

58. Wright, C. F., and R. S. Zitomer. 1984. A positive regulatory site and a negative regulatory site control expression of the Saccharomyces cerevisiae CYC7 gene. Mol. Cell. Biol. 4: 2023-2030.

59. Wright, C. F., and R. S. Zitomer. 1985. Point mutations implicate repeated sequences as essential elements of the $C Y C 7$ negative upstream site in Saccharomyces cerevisiae. Mol. Cell. Biol. 5:2951-2958. 